Inclusivity is a topic which is coming to the fore in many institutions, and libraries are no exception. To many of us, this may be a new area and could be somewhat daunting to begin to address. The authors provide some background, resources, and ideas to start to make your library inclusive, accessible, and welcoming to all patrons.-Editors

A wave of change is sweeping across research libraries in Canada and the United States as the value of inclusive learning is gaining rapid momentum. Buzz words like AODA, Human Rights Code, ADA, UDL, Section 508, VPAT, and WCAG are penetrating library conference programs and publications, ${ }^{1}$ but what does it really mean for a library to become compliant with legislative requirements or better yet, to go beyond the minimum requirements to become fully inclusive? Furthermore, what can libraries do to advocate on behalf of accessibility, take leadership roles in developing staff competencies, and promote the value of inclusive libraries to support users of all abilities? This article will look at accessibility through the lens of advocacy and the role of internal marketing in libraries to support, prepare, and inspire reference and user services staff to ignite valuable institutional change.

\section{BREAKING DOWN BARRIERS}

Katya Pereyaslavska $(M A, M I)$ is the Accessibility Initiatives Librarian for ScholarsPortal, Ontario Council of University Libraries and is currently seconded to the Association of Research Libraries as a Visiting Program Officer for Accessibility and Universal Design and tasked with raising awareness of inclusive library practices. Corinne Abba (MI) currently serves as Chair of the HLLRAODA Committee for Ontario College Libraries, promoting equitable access and accessibility initiatives aligned with the Accessibility for Ontarians with Disabilities Act (AODA).

Correspondence concerning this column should be directed to Nicole Eva and Erin Shea, email: nicole .eva@uleth.ca and eshea@fergusonlibrary.org.

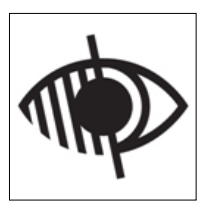

Although equity of access has long been a core principle of libraries throughout history, it is important to translate such principles into practice. Accessibility, much like assessment and copyright, is quickly becoming a core competency for new information professionals across different areas of specialization as it impacts staff in every library department from procurement to public service and administration. $^{2}$

The last few decades have marked somewhat of a renaissance in the development of technology as well as our understanding of what disability means in the twenty-first century. Jutta Treviranus, the Director of the Inclusive Research Design Centre at the Ontario College of Art and Design University, defines disability as a "mismatch between the needs of an individual and what their environment is able to offer." ${ }^{3}$ This understanding of disability removes its ownership from the individual and places it within the context of their environment. In this framework, anyone, at any point in their lives, may experience a disability barrier, be it from a temporary or permanent disability, visible or invisible. 
These barriers can occur when you are reaching for a suitcase with a child on your hip, when the designations of a washroom sign do not reflect a safe option for you, when you can no longer hear service announcements in public spaces, when dyslexia prevents you from finding your numbered classroom on time, or when you are trying to access public transit with a twisted ankle (to name only a few). In these scenarios we can see that it is the environment that challenges and often prevents safe and equal access. Why is this distinction an important paradigm shift for libraries? Because this changes the basic assumptions or contexts related to disability and accessibility. In this new framework an understanding of what accessibility means takes us away from looking at "curb cuts" to see if a wheelchair can access the library and moves us toward assessing it from a more holistic perspective; not with a single type of user in mind but by thinking about access and support based on many different "personas."

Beginning with an assessment phase, identifying and addressing barriers to access and working toward establishing a community of practice, library staff can truly engage with their community members in a more meaningful way. This includes pledging a public commitment to the principles of dignity, independence, integration, and equal opportunity, ${ }^{5}$ which motivate us to continually identify, remove and prevent barriers and to foster an environment in which everyone has increased opportunities to participate in our community.

Marketing these principles and the organization's commitment to removing barriers is an essential part of raising awareness and building an enthusiastic working culture that prioritizes services and offers support mechanisms that reach all members of our diverse communities. One important take away from this process is the reminder that one size does not fit all; the diversity of both our staff and our patrons should be reflected in the diversity of our solutions. And it is up to us, all library staff, to find flexible holistic solutions which support users of varying abilitiesbut first, we need buy-in. This is not simply an agreement to support accessibility initiatives, but a commitment and alignment of attitudes and goals within your library that impact organizational culture.

\section{MARKETING INCLUSIVITY: IT STARTS WITH YOUR OWN STAFF}

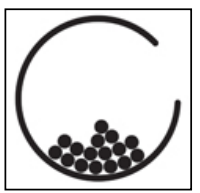

What's in a name? The buzz words are out there (ADA, UDL, AODA), but even if these acronyms are new to you, the underlying principles should resonate. Library staff may be familiar with some of the concepts that support accessibility principles and inclusive libraries through their knowledge of RUSA's Professional Competencies for Reference and User Services Librarians (2003), which prioritizes notions of access, responsiveness, and design of

\section{INTERNAL MARKETING TACTICS FOR LIBRARIES}

This quick cheat sheet highlights some initial steps that your library can take to improve internal marketing tactics in an effort to promote accessibility knowledge and competencies:

- Identify accessibility best practices and principles of inclusivity as fundamental to all library service.

- Provide comprehensive training to all staff that includes information about relevant legislation, policy, and procedures.

- Establish incentives and certification for training received.

- Benchmark yourself to see what other similar organizations are doing; a quick environmental scan should offer more insight.

- Create specific internal marketing messages that are relevant to the areas/departments within your institution (user services, reference, procurement, etc.).

- Encourage collaboration with other institutions, and within your own institution to support information exchange practices and to share training opportunities.

- Provide ongoing training and support, with continued access to resources such as toolkits and training videos.

- Develop a point person with knowledge of and interest in accessibility and support their training and expertise in this area.

- Once qualified, designate a specialist in inclusive librarianship to take the lead role in ensuring that all staff are up to date on current trends, news, tools and projects.

services. ${ }^{6}$ The base knowledge is likely already established throughout the library team and chances are your staff already provide some level of inclusive service on request (such as support with stack retrievals), so it becomes a matter of building the knowledge, expertise, and staff competencies in more conscious ways.

We can begin by ensuring that staff are aware of the basic principle of integrating accessibility into everything that they do (rather than it being situated as an add-on service or an extra step required). Once integration is securely established as the foundation of the service model, we can build from there. For internal marketing messages to be effective they need to remain focused and relevant, keeping in mind that the needs of your staff will inform how you train them. The needs of user service staff in the library will certainly differ from library technicians and librarians dealing with e-resources or collection development. It is important to take context into consideration, to know your obligations (under legislation, institutional policy, and local procedures), to be familiar with accessibility best practices, and to demonstrate an understanding of the diversity of user needs. 


\section{BUILDING COMPETENCIES}

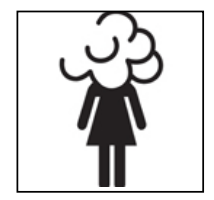

Creating staff resources and training sessions can be a daunting task, especially if you are also new to the field of accessibility. Our advice is to start by familiarizing yourself with relevant legislation. In Ontario we have several pieces of legislation that help guide our actions and policies as they relate to accessibility and public service, including: the Accessibility for Ontarians with Disabilities Act (AODA), ${ }^{7}$ the Ontario Human Rights Code,${ }^{8}$ and the Canadian Copyright Act. There are similar laws and regulations in the United States, including the Americans with Disabilities Act, ${ }^{9}$ Standards for Accessible Design, and Nondiscrimination Regulations. These will help establish compliance, but our work should endeavour to go beyond the minimum requirements to become fully inclusive.

Public services staff need to be well trained in the provision of accessible customer service, and work has already been done toward this goal, including the publication of government resources, toolkits for libraries, and related research in the field. There are also many institutions that are setting excellent examples of accessibility work that can be referenced as best practices.

One helpful starting point is for front line public services staff to demonstrate knowledge and awareness of accessibility apps and adaptive technologies (AT). The wealth of options in the area of assistive technologies (both open source freeware and paid software) can make staff training complicated. However, ensuring that all staff are well versed in most popular technologies such as screen readers or ZoomText can help to foster better quality interaction with library users. An active rapport with IT or AT support staff can help to ensure that this technology training is continuing and that your staff are on top of new and exciting inclusive tools for learning.

Behind the scenes it is essential that library resources and public service tools are evaluated for their usability and compatibility with these different assistive technologies. As an example we might consider assessing the benefits and accessibility features of reference services when delivered via online chat, phone, TTY, email, or in person. What chat tool is most compatible with screen readers and other adaptive technologies? Are your library's entrance, physical space, and reference desk accessible to all users? Establishing knowledge of and familiarity with ATs will help you and your staff understand user requirements. If you are unfamiliar with how to test for accessibility, it may be helpful to crowdsource this work by posting on relevant accessibility listservs such as the Alt Canform listserv (can-altform-bounces@linux -speakup.org). Alternatively you can reach out to other colleagues and specialists across local institutions, consortiums, and relevant organizations. When assessing the usability of any library service, staff should consider establishing a user advisory group comprised of diverse representatives of your user base. This group of regular library visitors has a critical role to play in establishing a peer to peer dialogue

\section{Training Resources}

- Web Accessibility Toolkit (Association of Research Libraries)

- $\quad$ Making Ontario Accessible: Customer Service Toolkit (Ministry of Economic Development, Employment and Infrastructure)

- Interactive AODA customer service training module (Council of Ontario Universities)

- Accessibility Information Toolkit for Libraries (Council of Ontario Universities)

- $\quad$ ADA Coordinator Training Certification Program (ACTCP) (University of Missouri)

\section{Best Practices}

- $\quad$ Creating Accessible Documents (Queen's University Accessibility Hub)

- $\quad$ Library Accessibility Resources (Guelph University)

- Accessible Campus (OCUL)

- Web Accessibility Toolkit for Libraries (ARL)

- AODA Procurement Toolkit (Ontario Colleges)

- Computer Software Accessibility Guidelines (ALA/ ASCLA)

- Improving Accessibility of Social Media (GSA)

with members of their own community helping you review the value of the services provided and helping you promote your commitment to accessibility and the range of services available to a wider audience.

As we consider our resources and spaces we should be sure to think about both the physical and the digital environment. Online learning continues to be an important access point and area of growth for many libraries; however, it comes with its own unique challenges of ensuring that the virtual learning environment is fully inclusive and that this awareness about the inclusivity of services reaches its targeted audiences-users of all abilities. As universal design and access principles have not yet been fully integrated into curriculum models across North America, it becomes increasingly important for libraries to consider how online learning and the resources and services libraries provide might create a more sustainable alternative for those who benefit from access to digital versus print materials. This might include college students who can study for an exam by listening to recorded lectures or library users who feel more confident asking questions online rather than in person, making the library's digital space, in many ways, a more democratic learning environment.

Toolkits offering step by step guidelines and best practices that address real world scenarios can serve as reference documents in the workplace, providing staff with valuable resources that can be incorporated into training guides, policies, and procedures. Developing a thoughtful accessibility policy enables all staff to have a clear and consistent understanding of what their institution is able to support and establishes a point of reference when they are faced with a specific situation in which a library user might want to know exactly what the library is able to offer them. In Ontario the AODA requirements link to many library-related services including print materials, customer service, procurement, 


\begin{tabular}{|c|c|}
\hline $\begin{array}{l}\text { “A Quick Gui } \\
\text { This quick gui } \\
\text { tools and tech } \\
\text { via computer }\end{array}$ & $\begin{array}{l}\text { e to Adaptive Technologies" } \\
\text { le can help familiarize staff with some of the } \\
\text { ologies often used to improve digital inclusion } \\
\text { ccessibility and usability. }{ }^{10}\end{array}$ \\
\hline & $\begin{array}{l}\text { Voice recognition software (such as Dragon } \\
\text { Naturally Speaking or Google Voice) uses voice } \\
\text { to dictate text instead of typing on a keyboard. }\end{array}$ \\
\hline & $\begin{array}{l}\text { Visual mapping software (such as Inspiration) } \\
\text { allows users to visually map ideas and outlines } \\
\text { and to brainstorm and visually communicate } \\
\text { concepts. It helps users structure writing, } \\
\text { and to prioritize and organize information for } \\
\text { projects, papers, and reports. }\end{array}$ \\
\hline & $\begin{array}{l}\text { Word prediction and text-to-speech software } \\
\text { (such as WordQ) predicts each word as } \\
\text { you type the letters and remembers words } \\
\text { previously used. This software reads the written } \\
\text { sentence back, allowing users to proofread their } \\
\text { work. }\end{array}$ \\
\hline & $\begin{array}{l}\text { Screen readers (such as JAWS) read aloud } \\
\text { what is on the computer screen and provide } \\
\text { user with tools for navigating and accessing } \\
\text { webpages and screen content. }\end{array}$ \\
\hline & $\begin{array}{l}\text { Reading, writing, and learning software (such } \\
\text { as Kurzweil) create notes by highlighting } \\
\text { electronic and scanned texts and allows users to } \\
\text { extract highlighted notes into a new document. } \\
\text { It reads text out loud (text-to-speech) and } \\
\text { allows users to save a document of electronic } \\
\text { text (such as a student's highlighted notes) to a } \\
\text { separate audio file. }\end{array}$ \\
\hline & $\begin{array}{l}\text { Magnification and screen reading software } \\
\text { (such as ZoomText) allow users to adjust screen } \\
\text { magnification, highlight cursor, screen color } \\
\text { scheme, and more. } \\
\text { Print magnifiers (such as SmartView or } \\
\text { CCTV) magnify print resources, such as } \\
\text { textbooks, library books, or print articles. }\end{array}$ \\
\hline & $\begin{array}{l}\text { Refreshable braille displays are "electronic } \\
\text { devices used to read text tactually that is } \\
\text { typically displayed visually on a computer } \\
\text { monitor." } \\
\text { "The advantages of a braille display over } \\
\text { synthetic speech are that it provides direct } \\
\text { access to information; allows the user to check } \\
\text { format, spacing, and spelling; and is quiet."11 }\end{array}$ \\
\hline
\end{tabular}

multimedia, and physical space; it is therefore essential that your library staff are able to understand how their workplace has addressed some of these standards. Some examples include Accessibility for Persons with Disabilities, Statement of Commitment (Guelph University) and Accessible Library Services Guide with ASL (George Brown College).

As part of your internal marketing program, libraries should consider creating incentives for staff to develop accessibility knowledge by providing certification of training received. As part of ongoing professional development discussions about accessibility, reviews of news items and newly developed tools should find their way into regular staff meetings. Advocacy really needs to start with staff internally for it to be successful with the library users as well.

Once library staff have a strong understanding of available tools and user experience with library resources, more proactive marketing and outreach efforts should take place to inform all library visitors of the options available to them. Staff are now equipped with the training and knowledge to highlight library policies and new resources designed to make your library a more equitable environment. Acting on a local level is great because it allows library staff to reach out directly to community members. However, thinking globally can ensure that the momentum of change has not been stalled. By establishing an active dialogue with libraries and accessibility organizations across the world, your own library can have the opportunity to benchmark itself against other important organizations, staying on top of valuable trends.

\section{DEVELOPING AND IMPLEMENTING ACCESSIBILITY INITIATIVES: ACE CASE STUDY}

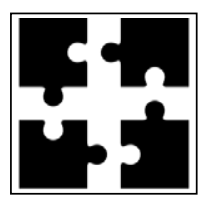

In 2012, the Ontario Council of University Libraries, in partnership with the University of Toronto Libraries, received a grant from the Accessibility Directorate of Ontario to pursue a pilot project to establish a shared infrastructure to host accessible texts for consortia members. The premise behind this project was quite broad: to develop a portal which would allow students and faculty with print disabilities access to library collections in a variety of formats on demand.

The Steering Committee was first tasked with identifying immediate stakeholders, developing a communications plan, and establishing milestones throughout the year-long pilot. In its first year, when the Accessible Content E-Portal (ACE) service was new and in the process of being defined, it was very important that staff at participating institutions were able to talk about the service in similar terms. As part of our internal marketing campaign we created and implemented the use of a unique project vocabulary, ensuring that students who interacted with ACE staff would receive consistent information about the project and reducing any confusion with regard to its scope.

As the project developed, creating advocacy tools on behalf of consortia members required the development of a series of awareness packages for staff as well as for end users. Webinars, LibGuides (guide 1 + guide 2), conference presentations, and updates via listservs were valuable methods of communication about the project in early phases, marking its milestones as well as rolling out the big announcement about the pilot becoming a core service. In the two years 


\section{AMPLIFY YOUR IMPACT}

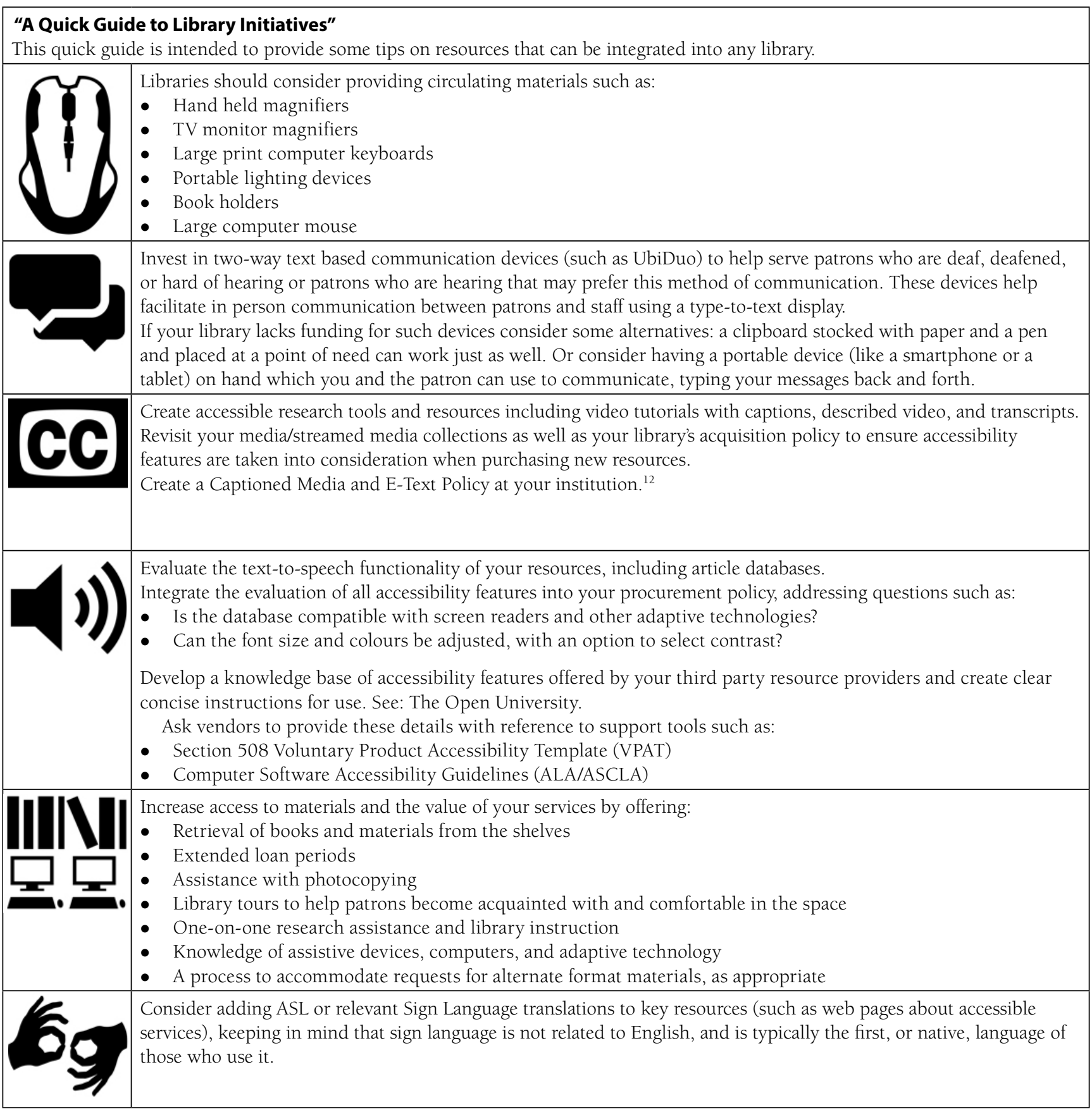

that followed, additional resources such as accessible guided tutorials (see tutorial 1 and tutorial 2) and bilingual posters and bookmarks in English and French were developed and shared with participating institutions.

As the ACE membership continued to grow, the value of regular communication with consortia members became increasingly important to support seventeen Ontario Universities who successfully rolled out the ACE service at their institutions as well as twenty-two Ontario Colleges who are currently accessing ACE via a year-long trial. Building these partnerships, consistently evaluating the service, and establishing measures to gauge its success are keys to the sustainability of this initiative.

\section{STATISTICS AND PARTNERSHIPS}

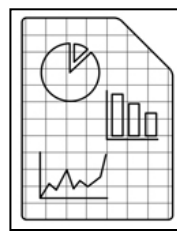

The evaluation of our services, resources and initiatives can begin with questions such as: What do users really need and how do we measure those needs? What standards of service provision should we aim for? Can end users help us define accessibility by designing their own inclusive learning tools? Intuitive navigation and serendipitous discovery are important but how do we track usage in a more flexible learning environment where our library visitors have control over manipulating formats and, to some degree, content? While advocacy and awareness are a 


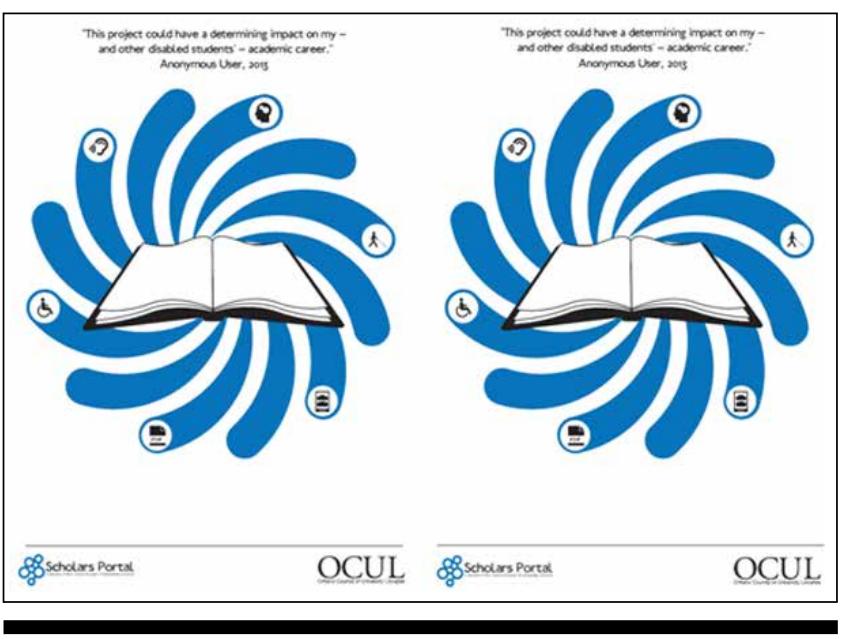

Figure 1. "ACE Service Flyer" (created July 2014)

part of the puzzle, peer to peer dialogue and involvement of the end users in the design process are as much a part of raising awareness as they are a part of a more holistic approach.

As your library works on developing an accessibility policy and initiatives, it's a good idea to reflect on what statistics are gathered to track user interactions which require technology assistance, referrals to accessibility specialists, or involve self declarations. In this context, accessibility work is very much a collective endeavour. We should include the expertise of different library departments to assess how user support can be tracked in more meaningful ways through user surveys, documentation pertaining to direct or remote interactions, and error reports. As another layer of our integrated approach to accessibility service, this shared evaluative process will encourage all staff to review the ways in which their services and resources support users of all abilities.

Advocacy plays a significant part in what our emerging role is as public or research libraries. As libraries begin to take on the role of content producers, our role of connecting content with audiences is becoming more complex. How do libraries work together to become the default "book place" and convince our users that our content is as "trustworthy" as the content publishers produce? Going beyond the library and forming good working relationships with local organizations, or reaching across the college or university to other entities on campus is a part of what libraries need to do to raise their profiles as trusted content producers or disseminators, helping us to become a part of a global movement that speaks to the world in one consistent voice to establish user trust.

\section{AMPLIFY YOUR IMPACT: DIVERSITY, INCLUSION AND ACCESSIBILITY}

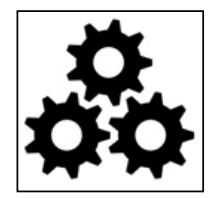

Working from a foundation of flexibility we hope the efforts of our institutions and library professionals establish a model that moves away from accommodation toward inclusivity. While some discussions tend to separate the discourse on accessibility from diversity and inclusion, we believe that they should go hand in hand. Inclusive librarianship is a movement recognizing that library staff and patrons are not a static group of people with identical interests and abilities. As Olga Dosis, the AODA Coordinator at George Brown College states: "Disability is diverse; a disability can be permanent, temporary, visible or invisible. Accessibility is not merely an issue of legal compliance or of meeting policy-related targets, accessibility is about providing equal opportunity and equal access for all."'3

Diversity and inclusion recognize that every individual has their own unique context coming from varying abilities, ethnic, and cultural backgrounds, and varying gender identity. When we think about library services we should recognize that while the notion of designated "safe spaces"14 within our institutions is a start, we should ask ourselves why the entire library can't be conceived as safe and inclusive for everyone?

As we continue to evolve, libraries serve an ever-growing diverse group of customers who-through their own needs, self-advocacy, and expertise-are moving library staff toward more innovative solutions for how resources are presented and services are designed. To build staff competencies and create champions of accessibility in our working environment we must market these broader concepts and goals to our staff, foster expertise in our departments, and develop initiatives by working directly with our stakeholders and members of our wider community. We can further communicate the value of accessibility services by expanding our work to the community at large, promoting inclusivity beyond our own immediate working environment.

We recognize that for most libraries, adopting an integrated accessibility model will entail a significant shift in organizational culture. This will take time, commitment, and support. And so, as we end this article, we would like to reiterate where this work can begin:

\section{"A QUICK GUIDE TO AMPLIFYING YOUR IMPACT"}

I-Invest in expertise and advocacy, training staff and building competency

M-Measure what services are already inclusive and build from there

P-Promote inclusive library services to staff, stakeholders, and to the community

A-Assess your services and the effectiveness of your initiatives

C-Collaborate with others to build inclusive libraries together

T-Transcend your current landscape by integrating accessibility into all library work going forward 


\section{AMPLIFY YOUR IMPACT}

\section{References}

1. AODA refers to the Accessibility for Ontarians with Disabilities Act, ADA to Americans with Disabilities Act, UDL to Universal Design for Learning, Section 508 to the amendment made to the United States' Rehabilitation Act that covers removing barriers to information technology, VPAT to Voluntary Product Accessibility Template, and WCAG to Web Content Accessibility Guidelines.

2. Unless otherwise noted, all images are taken from The Noun Project, https://thenounproject.com. "Blind" by Jordan Delcros; "Include" by James Keuning; "Head In The Clouds" by Luis Prado; "Public Information" Public domain image; "Presentation" by Garrett Knoll; "Document Text" by Thomas Helbig; "Data" by Wilson Joseph; "Media" by Jamison Wieser; "Magnifying Glass" by Boudewijn Mijnlieff; "Braille" Public domain image; "Mouse" by Mahmudxon; "Chat" Public domain image; "Speaker" by Harold Kim; "Library" by Pieter J. Smits; "Sign Language" Public domain image; "Resource" by Gilbert Bages; "Report" by Grant Fisher; "Gears" by Hubert Orlik-Grzesik.

3. Jutta Treviranus, "Superconference" (presentation, Ontario Library Association, 2014).

4. See Trenton Schulz and Kristin Skeide Fuglerud, "Creating Personas with Disabilities," in Computers Helping People with Special Needs Lecture Notes in Computer Science 7383 (2012): 145-52.

5. See Accessibility Standard for Customer Service: Employer Handbook, www.mcss.gov.on.ca/en/mcss/programs/acces sibility/customerService/guideToAccessibilityStandards/pol iciesPracticesProcedures.aspx.
6. RUSA Task Force on Professional Competencies, "Professional Competencies for Reference and User Services Librarians," approved by the RUSA Board of Directors, January 26, 2003, www.ala.org/rusa/resources/guidelines/professional.

7. Accessibility for Ontarians with Disabilities Act, S.O. 2005, c.11 (AODA) (2005)

8. Ontario Human Rights Code, R.S.O. 1990, c. H.19.

9. Americans With Disabilities Act of 1990. Public Law 101-336. 108th Congress, 2nd session (July 26, 1990).

10. This guide has been adapted from Kate Marczynski, "Adaptive Technology: Quick Guide for LLC Staff," created for George Brown College Library Learning Commons, 2012

11. "Refreshable Braille Displays," American Foundation for the Blind, 2014, accessed July 14, 2015, https://www.afb.org/Prod BrowseCatResults.asp?CatID=43.

12. "Universal Symbol for Closed Captioning," WGBH, logo created by Jack Foley, accessed June 28, 2015, http://main.wgbh.org/ wgbh/hire/symbols.html.

13. Olga Dosis, "Ontario Colleges' AODA Procurement Toolkit" (George Brown College, Diversity, Equity, Human Rights Services, January 2014), https://www.georgebrown.ca/aoda/pro curement-toolkit.docx.

14. See Michael R. Woodford et al., "Lesbian, Gay, Bisexual, and Transgender Ally Training Programs on Campus: Current Variations and Future Directions," Journal of College Student Development 55, no. 3 (2014): 317-22. 